\title{
A population based validation study of self-reported pensions and benefits: the Nord-Trøndelag health study (HUNT)
}

Solbjørg Makalani Myrtveit ${ }^{1,2^{*}}$, Anja M S Ariansen ${ }^{3,4}$, Ingvard Wilhelmsen ${ }^{5}$, Steinar Krokstad ${ }^{6}$ and Arnstein Mykletun 2,3,7

\begin{abstract}
Background: Measures of disability pensions, sickness certification and long-term health related benefits are often self-reported in epidemiological studies. Few studies have examined these measures, and the validity is yet to be established.

We aimed to estimate the validity of self-reported disability pension, rehabilitation benefit and retirement pension and to explore the benefit status and basic characteristics of those not responding to these items.

A large health survey (HUNT2) containing self-reported questionnaire data on sickness benefits and pensions was linked to a national registry of pensions and benefits, used as "gold standard" for the analysis. We investigated two main sources of bias in self-reported data; misclassification - due to participants answering questions incorrectly, and systematic missing/selection bias - when participants do not respond to the questions.

Sensitivity, specificity, positive (PPV) and negative (NPV) predicative value, agreement and Cohen's Kappa were calculated for each benefit. Co-variables were compared between non-responders and responders.

Results: In the study-population of 40,633, 9.2\% reported receiving disability pension, $1.4 \%$ rehabilitation benefits and $6.1 \%$ retirement pension. According to the registry, the corresponding numbers were $9.0 \%, 1.7 \%$ and $5.4 \%$. Excluding non-responders, specificity, NPV and agreement were above $98 \%$ for all benefits. Sensitivity and PPV were lower. When including non-responders as non-receivers, specificity got higher, sensitivity dropped while the other measures changed less.

Between $17.7 \%$ and $24.1 \%$ did not answer the questions on benefits. Non-responders were older and more likely to be female. They reported more anxiety, more depression, a higher number of somatic diagnoses, less physical activity and lower consumption of alcohol ( $p<0.001$ for all variables). For disability pension and retirement pension, non-responders were less likely to receive benefits than responders $(p<0.001)$. For each benefit $2.1 \%$ or less of non-responders were receivers. False positive responses were more prevalent than false negative responses.

Conclusions: The validity of self-reported data on disability pension, rehabilitation benefits and retirement pension is high - it seems that participants' responses can be trusted. Compared to responders, non-responders are less likely to be receivers. If necessary, power and validity can be kept high by imputing non-responders as non-receivers.
\end{abstract}

Keywords: Validity, Bias, Epidemiology, Non-responders

\footnotetext{
* Correspondence: makalani.myrtveit@med.uib.no

'Institute of medicine, University of Bergen, Bergen, Norway

${ }^{2}$ Norwegian Institute of Public Health, Division of Mental Health, Department of Public Mental Health, Bergen, Norway

Full list of author information is available at the end of the article
} 


\section{Background}

In epidemiological studies, self-reported information on disability pensions, sickness certification and long-term health related benefits is often used as exposure and/or outcome measures. The validity of such information can be challenged by different sources of biases [1,2]. For instance, individuals might choose not to participate, potentially leading to selection bias. Others might participate but not answer specific items. Participants might also answer questions incorrectly, leading to misclassification. Further, imputation procedures might introduce selection bias.

Multiple factors like sample population, cognitive abilities, recall time frame, questionnaire design, question comprehension and interpretation can affect the accuracy of self-reported information [3-7]. In general, research participants want to respond in ways that make them look as good as possible. For instance, in organizational behavioral research social desirability has been found significantly correlated with several widely used constructs like self-report of job performance, citizenship behavior and vitality $[8,9]$. Also other types of self-reported information seem affected by social desirability; for instance, a large downward bias in reporting food intake related to social desirability score has been found [10].

Reluctance to answer correctly or to answer at all can be seen when participants are questioned on issues perceived as stigmatizing or sensitive. Higher privacy provided in the information gathering process produce higher reported rates of alcohol consumption and other drug use [5]. Computer-assisted self-administered interviewing compared to computer-assisted personal interviewing result in higher reporting of both drug use and number of sexual partners [6]. However, participation rate seemed less affected by mode of data collection [6]. Also the validity of self-evaluated ability was associated with whether or not anonymity was guaranteed [7]. High intelligence, high achievement status and internal locus of control seem associated with more accurate evaluation of ability [7].

Whereas there are several studies of the validity of self-reported sickness-absence [11-21], there are only a few studies exploring validity of self-reported disability pension $[15,21,22]$. We are aware of no study investigating the validity of retirement pension or rehabilitation benefits. The studies that have been conducted mainly focused on the validity of answers, not investigating non-responders.

The aim of the current study was twofold: 1) to investigate the validity of self-reported disability pension, rehabilitation benefit and retirement pension, and 2) to explore the benefit status of participants not answering questions on benefits and pensions, and to explore demographic and health characteristics of non-responders. In order to do this, self-reported information from the population based dataset (HUNT2) was compared to a national register covering the total population.

\section{Methods}

\section{Study population}

Data from "Helseundersøkelsen i Nord-Trøndelag (the HUNT Study, HUNT2, 1995-1997)” were used. NordTrøndelag is one of 19 counties in Norway, and largely characteristic of the national population, though slightly less urban and with lower education attainment [23]. The HUNT2 Survey was conducted between August 1995 and March 1997. All inhabitants in Nord-Trøndelag County aged $>19(n=93,898)$ years received mailed questionnaires and an invitation to a clinical examination. The participation rate was $69.5 \%$ (65.4\% for men and $73.5 \%$ for women).

Most participants aged 70 years or older received a specialized questionnaire not including questions on benefit status and were therefor excluded from this study $(\mathrm{N}=7,733)$. In the end, $\mathrm{n}=40,633(\mathrm{n}=18,979$ men and $\mathrm{n}$ $=21,654$ women), mean age 44.6 years (SD: 13.4 years, range: 19 to 87 years) completed the questionnaire containing information needed in this study, and constituted our study population.

Like in previous studies [24], the data from HUNT2 were linked to FD-trygd using a unique 11-digit identification number assigned to all individuals living in Norway. FD-trygd is a historical event database often used in epidemiological research in Norway [25,26]. It contains information on topics like demography, social conditions, social security, employment, search for work and income for the entire Norwegian population from 1992 an onwards.

By linking these two datasets, we were able to validate participants' self-reported information on pensions/benefits (aim one), and to investigate non-responders and the possibility of systematic selection bias (aim two).

\section{Analytic samples}

Investigations of validity were conducted using the entire study-population of $n=40,633$. For exploration of characteristics of individuals not responding to the questions on benefits, information on co-variables was needed. Therefore, only individuals answering questions on co-variables were included and a subsample $n=34,262$ was used for these analysis.

\section{Register based accurate information}

Data on disability pension, rehabilitation benefits and retirement pension was found in FD-trygd, providing the base for evaluating self-reported information.

\section{Self-reported information on benefits}

Participants in HUNT2 were asked if they at time of participation received any social security benefit or pension, 
with the tick-off-possibilities: "Disability pension", "Retirement pension" or "Rehabilitation benefit".

Disability pension is to ensure a subsistence income for individuals with wage earning capacity permanently impaired due to an illness or injury [27]. It can be granted a $100 \%$ or graded (if graded, almost always as $50 \%$ or higher) [28].

Rehabilitation benefits are usually granted individuals with at least $50 \%$ disability. The benefit is supposed to help the disabled individual back into a position where he or she is able to work and function in society. Even when individuals are less than a 100\% disabled, and do have work ability left, most of the individual's time, energy and abilities are required for successful rehabilitation. Thus, the individual cannot work and rehabilitation benefit is usually granted $100 \%$ [28].

Retirement pensions from the Norwegian National Insurance Scheme ensure all citizens an income in their old age. The benefit can be received in 20, 40, 50, 60, 80 or $100 \%$ from 62 years of age, but it is usually received as $100 \%$ from 67 years of age [29].

\section{Self-reported information on co-variables}

Questions on co-variables were only asked for in HUNT2, with no corresponding objective information in FD-trygd. This data is therefore used as survey-data, and is not validated.

Gender was analyzed as a co-variable, as was marital status, grouped into "not married", "married", "separated/ divorced" or "widow/widower".

Participants' health was evaluated using questions on somatic diagnoses and symptoms of common mental disorders. Somatic diagnoses were recorded by ticking off for present or past cardiac infarction, angina pectoris, stroke, asthma, diabetes and/or multiple sclerosis.

Anxiety and depression were measured using the "Hospital Anxiety and Depression Scale" (HADS) [30], a widely used self-report questionnaire [31-33]. In accordance with previous studies, a valid rating of depression and anxiety was defined as at least 5 completed items at each sub-scale (HADS-S and HADS-D) [33,34], and the recommended cut-off score of $\geq 8$ was used in the descriptive table [31-33].

Health-related behavior was evaluated in line with previous studies $[35,36]$. The participants were asked "Do you smoke cigarettes, cigars and/or pipe daily" and grouped as smokers or non-smokers. Physical activity was evaluated by asking how often and for how long the participants engaged in both light and intense leisuretime physical activity. Amount of alcohol consumption was assessed using two questions: "Do you abstain from alcohol?" and "What is your normal consumption of alcoholic beverages within 14 days?". Based on this, using a cut-off value of 15 units, participants were grouped to have "no consumption", "moderate consumption", or "high consumption".

Questions on co-variables were answered by $n=34,262$ individuals. This subsample was used for investigating characteristics of those not responding to the questions on benefits.

\section{Statistics}

Aim one: Each benefit was evaluated separately using data sets from FD-trygd linked to HUNT2. The registered benefits in FD-trygd were set as the gold standard. For each benefit, a 2x3-table for comparison was made, displaying gold standard case and non-case against self-reported case, non-case and missing (Table 1). From these tables analyses were conducted. Excluding nonresponders, sensitivity (\% of true cases reported as cases), specificity (\% of true non-cases reported as noncases), positive predicative value (PPV) (\% of those set as cases that are true cases), and negative predicative value (\% of those set as non-cases that are true non-cases), agreement and Cohens Kappa were calculated for valid responses. Subsequently, the same measures were calculated again, with non-responders set as non-receivers.

Aim two: A table comparing co-variables between those answering and those not answering the questions on benefits also made, using the subsample $n=34,262$ (excluding those not answering questions on covariables). Chi-square test and two-tailed T-test were used to test if differences were significant.

STATA/IC 11 for Windows 7, PC, was used for all analyses.

\section{Ethics}

The data used are not openly available but were approved for use by Regional Committees for Medical and Health Research Ethics of Mid-Norway, Norway. All the participants in HUNT2 gave their written consent upon inclusion.

\section{Results}

\section{Study population}

The study population consisted of $n=40,633$ individuals. Among these, $53.3 \%$ were female and $3.3 \%$ were benefit receivers. The mean age 44.6 years (SD: 13.5 years, range: 19 to 87 years). The sample was predominantly Caucasian. Basic characteristics for the subsample answering questions on co-variables are presented in Table 2.

\section{Measures of validity, aim one}

For disability pension and retirement pension, the number of individuals reporting to be on the benefit was higher than the actual number of receivers according to the gold standard $(9.2 \%$ vs. $9.0 \%$ and $6.1 \%$ vs. $5.4 \%$ respectively) (Figure 1). For rehabilitation benefits $1.4 \%$ 
Table 1 Self-reported versus public registry information on disability pension, rehabilitation benefits and retirement pension, the HUNT Study (HUNT2, 1995-1997), $N=40,633$ aged 19-87 years

\begin{tabular}{|c|c|c|c|c|}
\hline & & \multicolumn{3}{|c|}{ Registry based information (gold standard) } \\
\hline & & Recipient of pension & Non-recipient & Total \\
\hline \multirow[t]{12}{*}{ Self-reported information } & Disability pension & $3,487(93.3 \%)$ & $251(6.7 \%)$ & $3,738(100 \%)$ \\
\hline & No disability pension & $46(0.2 \%)$ & $29,675(99.8 \%)$ & $29,721(100 \%)$ \\
\hline & Missing response & $129(1.8 \%)$ & $7,045(98.2 \%)$ & $7,174(100 \%)$ \\
\hline & Total & $3,662(9.0 \%)$ & $36,971(91.0 \%)$ & $40,633(100 \%)$ \\
\hline & Rehabilitation benefits & $419(72.2 \%)$ & $161(27.8 \%)$ & $580(100 \%)$ \\
\hline & No rehabilitation benefit & $94(0.3 \%)$ & $30,148(99.7 \%)$ & $30,242(100 \%)$ \\
\hline & Missing response & $181(1.8 \%)$ & $9,630(98.2 \%)$ & $9,811(100 \%)$ \\
\hline & Total & $694(1.7 \%)$ & $39,939(98.3 \%)$ & $40,633(100 \%)$ \\
\hline & Retirement pension & $2,047(83.2 \%)$ & $414(16.8 \%)$ & $2,461(100 \%)$ \\
\hline & No retirement pension & $39(0.1 \%)$ & $29,762(99.9 \%)$ & $29,801(100 \%)$ \\
\hline & Missing response & $93(1.1 \%)$ & $8,278(98.9 \%)$ & $8,371(100 \%)$ \\
\hline & Total & $2,179(5.4 \%)$ & $38,454(94.6 \%)$ & 40,633 (100\%) \\
\hline
\end{tabular}

Cross-table: Self-reported information on benefits versus public registry information. Data provided in numbers and percentages. Percentages calculated to equal $100 \%$ in rows.

Table 2 Basic characteristics of study population with valid answers for co-variables, the HUNT Study (HUNT2, 1995-1997), $\mathrm{N}=34,262$ aged $19-87$ years

\begin{tabular}{|c|c|c|c|c|}
\hline & $\begin{array}{l}\text { Female } \\
(\mathrm{N}=17,808)\end{array}$ & $\begin{array}{l}\text { Male } \\
(\mathrm{N}=16,454)\end{array}$ & P-values* & $\begin{array}{l}\text { Total } \\
(\mathrm{N}=34,262)\end{array}$ \\
\hline Female & $17,808(100 \%)$ & $0(0 \%)$ & & $17,808(52.0 \%)$ \\
\hline Age (mean (SD)) & $42.5(12.9)$ & $44.4(13.0)$ & $<.001$ & $43.4(13.0)$ \\
\hline Anxiety & $3,135(17.6 \%)$ & $2,083(12.7 \%)$ & $<.001$ & $5,218(15.2 \%)$ \\
\hline Depression & $1,544(8.7 \%)$ & $1,585(9.6 \%)$ & .002 & $3,129(9.1 \%)$ \\
\hline Somatic diagnosis $>0$ & $1,878(10.6 \%)$ & $2,310(14.0 \%)$ & $<.001$ & $4,188(12.2 \%)$ \\
\hline Physical activity & & & $<.001$ & \\
\hline No & $3,720(20.9 \%)$ & $3,947(24.0 \%)$ & & $7,667(22.4 \%)$ \\
\hline Moderate & $9,497(53.3 \%)$ & $6,661(40.5 \%)$ & & $16,158(47.2 \%)$ \\
\hline Heavy & $4,591(25.8 \%)$ & $5,846(35.5 \%)$ & & $10,437(30.5 \%)$ \\
\hline Consumption of alcohol & & & $<.001$ & \\
\hline No consumption & $5,877(33.0 \%)$ & $3,176(19.3 \%)$ & & $9,053(26.4 \%)$ \\
\hline Moderate consumption & $11,788(66.2 \%)$ & 12,477 (75.8\%) & & $24,265(70.8 \%)$ \\
\hline Heavy consumption & $143(0.8 \%)$ & $801(4.9 \%)$ & & $944(2.8 \%)$ \\
\hline Smoking & $6,110(34.3 \%)$ & 4,973 (30.2\%) & $<.001$ & $11,083(32.4 \%)$ \\
\hline Marital status & & & $<.001$ & \\
\hline Married & $11,059(62.1 \%)$ & 10,078 (61.3\%) & & $21,137(61.7 \%)$ \\
\hline Not married & $4,585(25.8 \%)$ & $5,076(30.9 \%)$ & & $9,661(28.2 \%)$ \\
\hline Separated or divorced & $1,475(8.3 \%)$ & $1,109(6.7 \%)$ & & $2,584(7.6 \%)$ \\
\hline Widow/Widower & $688(3.9 \%)$ & $189(1.2 \%)$ & & $877(2.6 \%)$ \\
\hline Self-reporting disability pension & $1,529(8.6 \%)$ & $1,108(6.7 \%)$ & $<.001$ & $2,637(7.7 \%)$ \\
\hline Self-reporting rehabilitation benefit & $268(1.5 \%)$ & $226(1.4 \%)$ & .087 & $494(1.4 \%)$ \\
\hline Self-reporting retirement pension & $667(3.8 \%)$ & $906(5.5 \%)$ & $<.001$ & $1,573(4.6 \%)$ \\
\hline
\end{tabular}

*testing if there is a significant difference between genders, chi-square test/T-test. 


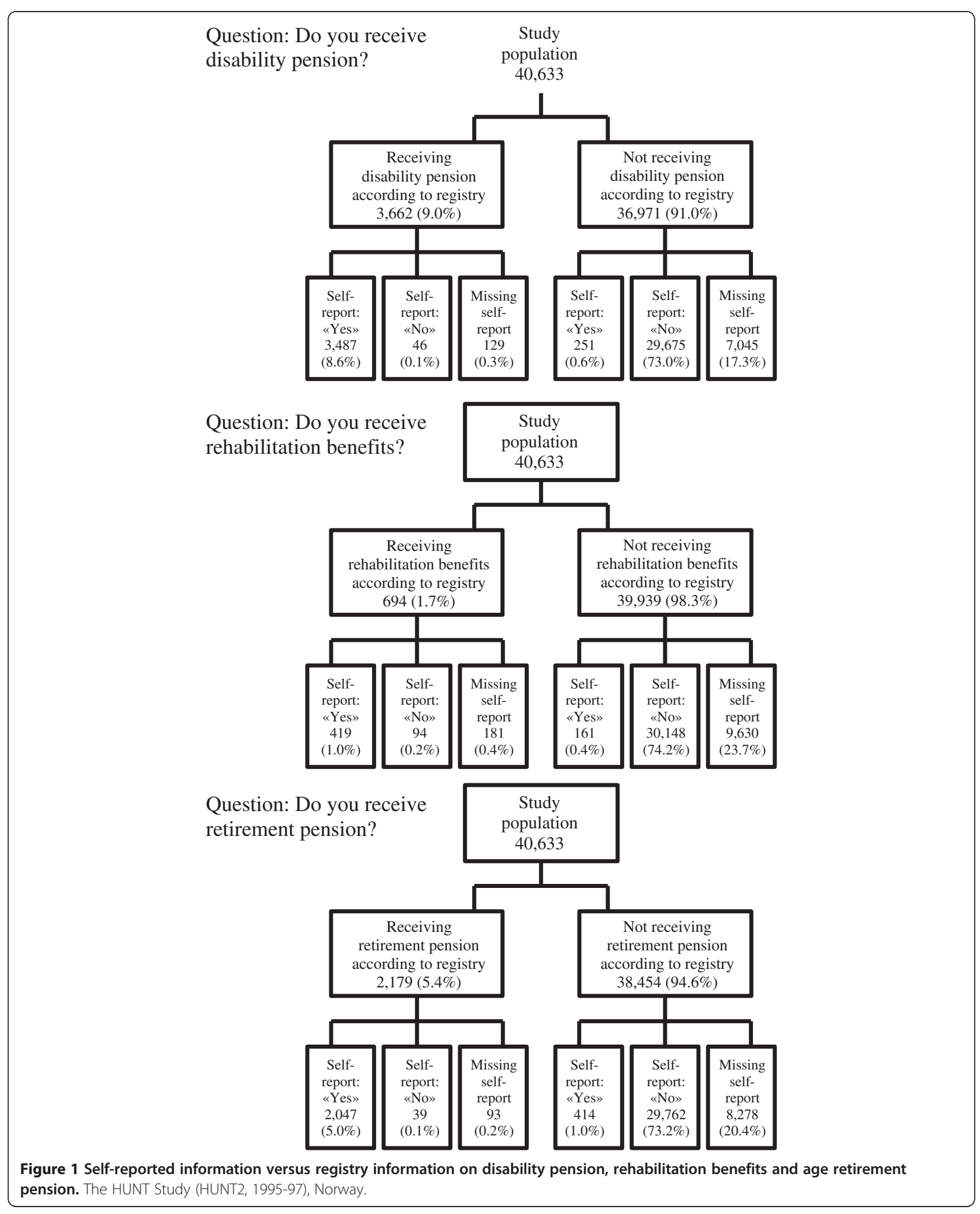


reported to receive it while $1.7 \%$ did. For disability pension $17.7 \%$, for rehabilitation benefit $24.1 \%$ and for retirement pension $20.6 \%$ did not answer.

For disability pension and retirement pension, sensitivity, specificity, negative predicative value (NPV) and agreement for answers only were all above 98\% (Table 3). The positive predicative value (PPV) was 93.3\% and $83.2 \%$ respectively, and Cohen's kappa was 0.95 and 0.89 . When non-responders were set as nonreceivers, specificity got higher, PPV remained the same and NPV, sensitivity, Cohen's kappa and agreement fell. The same trend was found for rehabilitation benefits. Specificity for rehabilitation benefits was higher than the specificity for the two other pensions, while all other measures of validity were lower.

\section{Characteristics of individuals not responding to questions on benefits, aim two}

For disability pension and retirement pension, nonresponders were less likely to be receivers than those responding (self-report overestimate rate of reception) $(\mathrm{p}<0.001)$ (Table 4). For rehabilitation benefits, 1.6\% of responders and $2.1 \%$ of non-responders were receivers $(\mathrm{p}=0.004)$.

Non-responders were generally older and more likely to be female. They reported more anxiety, more depression and more somatic diagnosis. They were less physically active and reported a lower consumption of alcohol. They smoked more and were for disability pension and retirement pension less likely to be married.

\section{Discussion}

\section{Summary of findings}

Measures of validity for answers only were very high for both disability pension and retirement pension, somewhat lower for rehabilitation benefits. For all three benefits, sensitivity, specificity and NPV were high, PPV slightly lower. Non-responders were found to be mainly non-receivers. Imputing non-responders as non-receivers led to falling measures of validity - though sensitivity, specificity and NPV were kept above $90 \%$ for all benefits except rehabilitation benefits.

\section{Strengths and limitations}

A major strength of this study is that it was conducted in a country with a common public social security system virtually utilized by all. Also, the complete nationwide registry containing inter alia information on pensions and benefits is a great advantage. The registry data is complete without missing, and the quality of the data is very high. The ability to link this registry, using a unique 11-digit identification number assigned to all individuals living in Norway, to the large, population-based survey, HUNT2, gave ideal conditions for analyzing validity of self-reported data.

In HUNT2 participants were asked "Are you currently receiving any of these public benefits". The specific date of participation was then linked to the corresponding register-data, reducing the problem of recall bias seen in retrospectively collected data [37].

The study also has some notable limitations. Although the study-sample was large and the participation-rate at

Table 3 Validity of self-reported information on disability pension, rehabilitation benefits and retirement pension, the HUNT Study (HUNT2, 1995-1997), N= 40,633 aged 19-87 years

\begin{tabular}{|c|c|c|c|c|c|c|}
\hline & $\begin{array}{l}\text { Sensitivity } \\
(\%)\end{array}$ & $\begin{array}{l}\text { Specificity } \\
(\%)\end{array}$ & $\begin{array}{l}\text { Positive predicative } \\
\text { value }(\%)\end{array}$ & $\begin{array}{l}\text { Negative predicative } \\
\text { value (\%) }\end{array}$ & Kappa & $\begin{array}{l}\text { Agreement } \\
(\%)\end{array}$ \\
\hline \multicolumn{7}{|l|}{ Disability pension } \\
\hline Answers only & 98.7 & 99.2 & 93.3 & 99.8 & 0.95 & 99.1 \\
\hline$(95 \% \mathrm{Cl})$ & (98.3-99.1) & (99.1-99.3) & $(92.5-94.1)$ & (99.8-99.9) & & \\
\hline Missing set as non-recipient & 95.2 & 99.3 & 93.3 & 99.5 & 0.94 & 99.0 \\
\hline$(95 \%$ Cl) & $(94.5-95.9)$ & $(99.2-99.4)$ & $(92.5-94.1)$ & (99.5-99.6) & & \\
\hline \multicolumn{7}{|l|}{ Rehabilitation benefits } \\
\hline Answers only & 81.7 & 99.5 & 72.2 & 99.7 & 0.76 & 99.2 \\
\hline$(95 \% \mathrm{Cl})$ & $(78.3-85.0)$ & (99.4-99.6) & $(68.6-75.9)$ & (99.6-99.8) & & \\
\hline Missing set at non-recipient & 60.4 & 99.6 & 72.2 & 99.3 & 0.65 & 98.9 \\
\hline$(95 \%$ Cl) & $(56.7-64.0)$ & $(99.5-99.7)$ & $(68.6-75.9)$ & (99.2-99.4) & & \\
\hline \multicolumn{7}{|l|}{ Retirement pension } \\
\hline Answers only & 98.1 & 98.6 & 83.2 & 99.9 & 0.89 & 98.6 \\
\hline$(95 \% \mathrm{Cl})$ & $(97.5-98.7)$ & $(98.5-98.8)$ & $(81.7-84.7)$ & (99.8-99.9) & & \\
\hline Missing set as non-recipient & 93.9 & 98.9 & 83.2 & 99.7 & 0.88 & 98.7 \\
\hline$(95 \%$ Cl) & (92.9-94.9) & (98.8-99.0) & $(81.7-84.7)$ & (99.6-99.7) & & \\
\hline
\end{tabular}


Table 4 Comparing non-responders and responders, the HUNT Study (HUNT2, 1995-1997), N = 34,262 aged 19-87 years

\begin{tabular}{|c|c|c|c|c|c|c|c|c|c|c|}
\hline & \multicolumn{3}{|c|}{ Disability pension } & \multicolumn{3}{|c|}{ Rehabilitation benefit } & \multicolumn{4}{|c|}{ Retirement pension } \\
\hline & $\begin{array}{l}\text { Valid answer } \\
(\mathrm{N}=\mathbf{2 8 , 8 4 7})\end{array}$ & $\begin{array}{l}\text { No answer } \\
(\mathrm{N}=5,415)\end{array}$ & P-values* & $\begin{array}{l}\text { Valid answer } \\
(\mathrm{N}=27,105)\end{array}$ & $\begin{array}{l}\text { No answer } \\
(\mathrm{N}=7,157)\end{array}$ & P-values* & $\begin{array}{l}\text { Valid answer } \\
(\mathrm{N}=27,853)\end{array}$ & $\begin{array}{l}\text { No Answer } \\
(\mathrm{N}=6,409)\end{array}$ & P-values* & $\begin{array}{c}\text { Total } \\
(\mathrm{N}=34,262)\end{array}$ \\
\hline Female & $50.9 \%$ & $57.9 \%$ & $<0.001$ & $50.4 \%$ & $57.8 \%$ & $<0.001$ & $50.3 \%$ & $59.1 \%$ & $<0.001$ & $52.0 \%$ \\
\hline Age (mean, in years) & 42.4 & 48.7 & $<0.001$ & 41.4 & 51.1 & $<0.001$ & 42.5 & 47.4 & $<0.001$ & 43.4 \\
\hline (SD) & (12.3) & $(15.2)$ & & $(11.8)$ & $(14.2)$ & & $(12.7)$ & & & $(13.0)$ \\
\hline Anxiety & $14.7 \%$ & $18.2 \%$ & $<0.001$ & $13.9 \%$ & $20.1 \%$ & $<0.001$ & $13.6 \%$ & $22.4 \%$ & $<0.001$ & $15.2 \%$ \\
\hline Depression & $8.6 \%$ & $11.9 \%$ & $<0.001$ & $7.9 \%$ & $13.9 \%$ & $<0.001$ & $7.9 \%$ & $14.6 \%$ & $<0.001$ & $9.1 \%$ \\
\hline Somatic diagnosis $>0$ & $11.6 \%$ & $15.7 \%$ & $<0.001$ & $10.4 \%$ & $19.0 \%$ & $<0.001$ & $11.0 \%$ & $17.6 \%$ & $<0.001$ & $12.2 \%$ \\
\hline Physical activity & & & $<0.001$ & & & $<0.001$ & & & $<0.001$ & \\
\hline No & $22.3 \%$ & $23.1 \%$ & & $21.8 \%$ & $24.8 \%$ & & $21.6 \%$ & $25.7 \%$ & & $22.4 \%$ \\
\hline Moderate & $46.3 \%$ & $51.9 \%$ & & $45.6 \%$ & $53.0 \%$ & & $46.3 \%$ & $51.0 \%$ & & $47.2 \%$ \\
\hline Heavy & $31.5 \%$ & $25.1 \%$ & & $32.6 \%$ & $22.2 \%$ & & $32.1 \%$ & $23.3 \%$ & & $30.5 \%$ \\
\hline Consumption of alcohol & & & $<0.001$ & & & $<0.001$ & & & $<0.001$ & \\
\hline No consumption & $25.5 \%$ & $31.6 \%$ & & $24.1 \%$ & $35.1 \%$ & & $24.8 \%$ & $33.3 \%$ & & $26.4 \%$ \\
\hline Moderate consumption & $71.7 \%$ & $66.3 \%$ & & $72.9 \%$ & $62.9 \%$ & & $72.3 \%$ & $64.4 \%$ & & $70.8 \%$ \\
\hline Heavy consumption & $2.9 \%$ & $2.2 \%$ & & $3.0 \%$ & $2.0 \%$ & & $2.9 \%$ & $2.3 \%$ & & $2.8 \%$ \\
\hline Smoking & $31.4 \%$ & $37.4 \%$ & $<0.001$ & $30.9 \%$ & $37.9 \%$ & $<0.001$ & $30.7 \%$ & $39.7 \%$ & $<0.001$ & $32.4 \%$ \\
\hline Marital status & & & $<0.001$ & & & $<0.001$ & & & $<0.001$ & \\
\hline Married & $62.3 \%$ & $58.7 \%$ & & $61.6 \%$ & $62.0 \%$ & & $62.4 \%$ & $58.6 \%$ & & $61.7 \%$ \\
\hline Not married & $29.0 \%$ & $24.2 \%$ & & $30.2 \%$ & $20.7 \%$ & & $29.2 \%$ & $23.9 \%$ & & $28.2 \%$ \\
\hline Separated or divorced & $7.3 \%$ & $8.8 \%$ & & $7.1 \%$ & $9.3 \%$ & & $6.8 \%$ & $10.8 \%$ & & $7.6 \%$ \\
\hline Widow/Widower & $1.5 \%$ & $8.3 \%$ & & $1.1 \%$ & $8.0 \%$ & & $1.6 \%$ & $6.8 \%$ & & $2.6 \%$ \\
\hline Self-reported disability pension & $9.1 \%$ & & & & & & & & & $7.7 \%$ \\
\hline Receiving disability pension & $8.6 \%$ & $1.5 \%$ & $<0.001$ & & & & & & & $7.5 \%$ \\
\hline Self-reported rehabilitation benefit & & & & $1.8 \%$ & & & & & & $1.4 \%$ \\
\hline Receiving rehabilitation benefit & & & & $1.6 \%$ & $2.1 \%$ & $=0.004$ & & & & $1.7 \%$ \\
\hline Self-reported retirement pension & & & & & & & $5.7 \%$ & & & $4.6 \%$ \\
\hline Receiving retirement pension & & & & & & & $4.6 \%$ & $0.9 \%$ & $<0.001$ & $3.9 \%$ \\
\hline
\end{tabular}

${ }^{*}$ testing if there is a significant difference between those answering and those not answering, chi-square test/T-test. 
baseline was high (69.5\%), no data on benefits were available for non-participants. A study investigating HUNT3 (the third wave of the HUNT-study) found the rate of benefits to be higher amongst the non-attendees than amongst participants [38]. This was also the case in HUSK, a comparable study, but with a more limited age-range [39]. Thus, selection bias, possibly reducing generalizability [37], cannot be ruled out.

The pensions here investigated are ususally granted as a $100 \%$, but can also be granted graded. It could have been interesting to investigate differences in validity between individuals receiving benefits as a $100 \%$ and those receiving much less. In our study population, however, this was not possible. Amongst individuals receiving disability pension, $0.10 \%$ received it as less than $50 \%$. Amongst those receiving rehabilitation benefits, $0.79 \%$ received less than $50 \%$. For the major part of individuals receiving retirement pension, we have no data on grading. In a subsample of $\mathrm{n}=859$ containing this information, $0.02 \%$ individuals received less than $50 \%$ retirement pension. Due to the small number of individuals receiving less than $50 \%$ benefits, we do not consider it ethically justifiable or meaningful to investigate these individuals further.

Also, the data investigated was collected between 1995 and 1997, and the measures of validity found are from this time. Even if the proportion of people granted pensions and benefits might change over time, we see no reason to believe this to affect how truthfully participants report their benefit situation. However, as discussed below, PPV and NPV are measures dependent on the prevalence of the condition studied and might therefore change more with varying prevalence than sensitivity and specificity. Though we do not expect the validity of self-reported pensions and benefits to have changed greatly since 1995, measures of validity should also be investigated in newer datasets.

\section{Interpreting of findings}

The high validity found in this study, and that specificity is higher than sensitivity and NPV higher than PPV, shows that non-receivers can be correctly classified based on self-report. This is in line with previous findings [21].

A reason for lower sensitivity than specificity could be unwillingness to reveal personal circumstances. Reluctance to answer questions, or to answer them correctly, could be expected if people consider the information sensitive. Social desirability has been found important for validity of self-reported information on for instance job performance, citizenship behavior, vitality and dietary intake [8-10]. If this is the case also for self-report of benefit receipt, we would expect to see under-reporting. In our study, however, participants getting their answers wrong mainly over-reported. For disability pension and retirement pension non-responders were less likely to be receivers than the group in total. Social desirability and reluctance to answer sensitive questions correctly can therefore not explain our findings.

False positive answers could be explained if participants knew they were receiving money - but not which benefit - and ticked off for the wrong one. Investigating false positives, for disability pension $43.4 \%$ of these, for rehabilitation benefits $22.4 \%$ and for retirement pension $20.3 \%$ received one of the other benefits evaluated. This percentage might possibly be even higher: Participants here grouped as false positives could receive benefits that we do not have data on (social benefits, survivors' benefits etc.). This cannot be evaluated in this study.

Another consequence of participants being unsure which benefit they received could be ticking off for more than one benefit. This could also lead to false positive answers. In our data, only $n=45$ participants ticked off for two benefits, none for three. This can therefore not explain the over-reporting.

While sensitivity and specificity are independent of the prevalence of the situation being studied, PPV and NPV are not. At low prevalence false positives will tend to overwhelm true positives, resulting in a falling PPV. At the same time, true negative will tend to overwhelm false negative and the NPV will rise with falling prevalence [40]. This is reflected in our study - where, for all three benefits, the prevalence is low and NPV higher than PPV. Further, the prevalence for rehabilitation benefits is lower than the prevalence of the other benefits. This might explain the even lower PPV and the high NPV for this benefit.

Though some participants got their answers wrong, and sensitivity and PPV was somewhat lower than specificity and NPV, estimates of validity were very high. This is in line with previous studies $[21,22]$ and indicates that research based on self-reported data on pensions is of good quality, and that participants answering to a great extent can be trusted.

Problems arise with individuals not answering. For all three benefits investigated, between $17.7 \%$ and $24.1 \%$ did not answer the specific question on benefits. Studies excluding individuals not answering specific questions might experience a drastic decline of power. Also, systematic differences between responders and non-responders can lead to selection bias when excluding these individuals. In our study, individuals not responding to the questions on benefit receipt reported more anxiety, more depression and more somatic diagnosis. They were less physical activity and smoked more. These findings are to a large extent comparable to characteristics of non-participants and drop-outs $[39,41,42]$.

Research is often focused on individuals with physical, mental or social problems. The fact that these individuals to a larger extent than healthy individuals do not answer, 
or answer questions incorrectly, should be noted. Excluding non-responders to specific items might therefore exclude the individuals we are interested in investigating.

In order to avoid decline in power and the selection bias seen when excluding non-responders, non-responders could be included in the study. The risk of receiving the benefits we investigated when not responding was $2.1 \%$ or less. Our results show that by setting non-responders as non-receivers validity is kept high.

\section{Conclusion}

The validity of self-reported data on disability pension, rehabilitation benefits and retirement pension was found to be high: it seems that participants answering can be trusted. This indicates that self-reported data on different pensions and benefits are useful in epidemiological studies. A considerable proportion of participants, however, do not answer questions on benefits. Excluding these can lead to selection bias and a drastic decline of power. For disability pension and retirement pension non-responders were less likely to be receivers than responders. As $2.1 \%$ or less of non-responders were receivers, these participants can be imputed to non-receivers, keeping power and validity high. Due to possible systematic differences between non-participants and participants, future research should seek to examine the possible effect on validity and generalizability caused by selection bias due to nonparticipation.

\section{Abbreviations \\ PPV: Positive predicative value; NPV: Negative predicative value.}

\section{Competing interests}

The authors declare that they have no competing interests.

\section{Authors' contributions \\ Mykletun designed the study, while authors Wilhelmsen, Ariansen and Myrtveit contributed further to the scope of the study. Myrtveit conducted literature searches, and provided summaries of previous studies. Myrtveit conducted the statistical analysis under supervision of Ariansen and Mykletun. Krokstad initiated studies on social security benefits in HUNT, provided and quality assured data. All authors contributed to the interpretation of findings, and Myrtveit wrote the first draft of the manuscript. All authors contributed to the further refinement of the manuscript and approved the final version.}

\section{Acknowledgements}

Data were obtained from the Norwegian Office for Social Insurance and The Nord-Trøndelag Health Study (The HUNT Study, a collaboration between HUNT Research Centre, Faculty of Medicine, Norwegian University of Science and Technology (NTNU, Verdal), Norwegian Institute of Public Health, and Nord-Trøndelag County Council). The first author was funded by a carrier grant from the Faculty of Medicine and Dentistry, University of Bergen.

\section{Author details}

${ }^{1}$ Institute of medicine, University of Bergen, Bergen, Norway. ${ }^{2}$ Norwegian Institute of Public Health, Division of Mental Health, Department of Public Mental Health, Bergen, Norway. ${ }^{3}$ Department of Health Promotion and Development, Faculty of Psychology, University of Bergen, Bergen, Norway. ${ }^{4}$ Faculty of social sciences, University of Bergen, Bergen, Norway. ${ }^{5}$ Department of Medicine, Haraldsplass Deaconal Hospital, Bergen, Norway. ${ }^{6}$ HUNT Research Centre, Department of Public Health and General Practice,
Norwegian University of Science and Technology, Trondheim, Norway. ${ }^{7}$ University of New South Wales, School of Psychiatry, Sydney, Australia.

Received: 8 June 2012 Accepted: 17 January 2013

Published: 23 January 2013

\section{References}

1. Delgado-Rodríguez M, Llorca J: Bias. J Epidemiol Community Health 2004, 58:635-641.

2. Rothman KJ, Greenland S, Lash TL: Validity in Epidemiologic Studies, Modern epidemiology. Philadelphia: Wolters Kluver Health, Lippincott Williams \& Wilkins; 1998:128-147.

3. Bhandari A, Wagner T: Self-reported utilization of health care services: improving measurement and accuracy. Med Care Res Rev 2006, 63:217-235.

4. West S, SB L, Poole C: Validity of pharmacoepidemiologic drug and diagnosis data. In Pharmacoepidemiology. Edited by SB L. Chichester, West Sussex: John Wiley and Sons; 2005:709-766.

5. Brener ND, Billy JOG, Grady WR: Assessment of factors affecting the validity of self-reported health-risk behavior among adolescents: evidence from the scientific literature. J Adolesc Health 2003, 33:436-457.

6. Tourangeau R, Smith TW: Asking sensitive questions the impact of data collection mode, question format, and question context. Public Opin Q 1996, 60:275-304.

7. Mabe PA, West SG: Validity of self-evaluation of ability: A review and meta-analysis. J Appl Psychol 1982, 67:280.

8. Moorman RH, Podsakoff PM: A metaanalytic review and empirical test of the potential confounding effects of social desirability response sets in organizational behaviour research. J Occup Organ Psychol 2011, 65:131-149.

9. Donaldson SI, Grant-Vallone EJ: Understanding self-report bias in organizational behavior research. J Bus Psychol 2002, 17:245-260

10. Hebert JR, Clemow L, Pbert L, Ockene IS, Ockene JK: Social desirability bias in dietary self-report may compromise the validity of dietary intake measures. Int J Epidemiol 1995, 24:389-398.

11. Voss M, Stark S, Alfredsson L, Vingård E, Josephson M: Comparison of self-reported and register data on sickness absence among public employees in Sweden. Occup Environ Med 2008, 65:61-67.

12. van Poppel MNM, de Vet HCW, Koes BW, Smid T, Bouter LM: Measuring sick leave: a comparison of self-reported data on sick leave and data from company records. Occup Med 2002, 52:485-490.

13. Short ME, Goetzel RZ, Pei X, Tabrizi MJ, Ozminkowski RJ, Gibson TB, Dejoy DM, Wilson MG: How accurate are self-reports? Analysis of self-reported helath care utilization and absence when compared with administrative data. J Occup Environ Med 2009, 51:786-796

14. Laestadius JG, Ye J, Dimberg L: Can we trust the answers? Reliability and validity of self-reported sick leave due to musculoskepletal symptoms. J Occup Environ Med 2008, 50:611-612.

15. Øyeflaten I, Lie SA, Ihlebæk C, Brage S, Eriksen HR: Comparison of self-reported and register data on sickness absence among Norwegian patients participating in an occupational rehabilitation program. Norwegian Journal of Epidemiology 2009, 19:161-167.

16. Fredriksson $\mathrm{K}$, Toomingas A, Torgen $M$, Thorbjornsson CB, Kilbom A: Validity and reliability of self-reported retrospectively cellected data on sick leave related to musculoskeletal disorders. Scand I Work Environ Health 1998, 24:425-431.

17. Ferrie JE, Kivimaki M, Head J, Shipley M, Vahtera J, Marmot MG: A comparison of self-reported sickness absence with absences recorded in employers' registers: evidence from the Whitehall II study. Occup Environ Med 2005, 62:74-79.

18. Burdorf A, Post W, Bruggeling T: Reliability of a questionnaire on sickness absence with specific attention to absence due to back pain and respiratory complaints. Occup Environ Med 1996, 53:58-62.

19. Pole JD, Franche RL, Hogg-Johnson S, Vidmar M, Krause N: Duration of work disability: a comparison of self-report and administrative data. Am J Ind Med 2006, 49:394-401.

20. Agius RM, Lloyd MH, Campbell S, Hutchison P, Seaton A, Soutar CA: Questionnaire for the identification of back pain for epidemiological purposes. Occup Environ Med 1994, 51:756-760.

21. Sveberg P, Ropponen A, Lichtenstein P, Alexanderson K: Are self-report of disability pension and long-term sickness absence accurate? Comparison 
of self-reported interview data with national register data in Swedish twin cohort. BMC Publ Health 2010, 10:763.

22. Hartz I, Tverdal A, Skurtveit S: A comparison of self-reported data on disability pension status with data from nationwide administrative register. Norwegian Journal of Epidemiology 2009, 19:169-172.

23. Mykletun A, Bjerkeset O, Overland S, Prince M, Dewey M, Stewart R: Levels of anxiety and depression as predictors of mortality: the HUNT study. Br J Psychiatry 2009, 195:118-125.

24. Krokstad S, Westin S: Disability in society-medical and non-medical determinants for disability pension in a Norwegian total county population study. Soc Sci Med 2004, 58:1837-1848.

25. Østby KA, Ørstavik RE, Knudsen AK, Reichborn-Kjennerud T, Mykletun A: Health problems account for a small part of the association between socioeconomic status and disability pension award. Results from the Hordaland Health Study. BMC Publ Health 2011, 11:12.

26. Haukenes I, Mykletun A, Knudsen AK, Hansen HT, Mæland JG: Disability pension by occupational class-the impact of work-related factors: The Hordaland Health Study Cohort. BMC Publ Health 2011, 11:406.

27. The Norwegian Labour and Welfare Service (NAV): December 5th 2012. Disability pension Web-page; 2012. http://www.nav.no/English/English/ Uførepensjon.284220.cms.

28. Kjønstad A: Folketrygdsytelser i omstillingsperioder. In Innføring i trygderett. Edited by edition. Otta: Tano Aschehoug AS; 1998:66-104.

29. Retirement pension, web-page. 2012. http://www.nav.no/Pensjon/ Alderspensjon/Fakta+om/_attachment/269922?_ts=1398c1447d.

30. Zigmond A, Snaith R: The hospital anxiety and depression scale. Acta Psychiatr Scand 1983, 67:361-370.

31. Herrmann C: International experiences with the hospital anxiety and depression scale - A review of validation data and clinical results. J Psychosom Res 1997, 42:17-41.

32. Bjelland I, Dahl A, Haug T, Neckelmann D: The validity of the hospital anxiety and depression scale. An updated literature review. J Psychosom Res 2002, 52:69-77.

33. Olsson I, Mykletun A, Dahl A: The hospital anxiety and depression rating scale: a cross-sectional study of psychometrics and case finding abilities in general practice. BMC Psychiatry 2005, 5:46-46.

34. Haug $\Pi$, Mykletun A, Dahl AA: The association between anxiety, depression, and somatic symptoms in a large population: The HUNT-II study. Psychosom Med 2004, 66:845-851.

35. Skogen JC, Harvey S, Henderson M, Stordal E, Mykletun A: Anxiety and depression among abstainers and low-level alcohol consumers.The Nord-Trøndelag Health Study. Addiction 2009, 104:1519-1529.

36. Harvey SB, Hotopf M, Overland S, Mykletun A: Physical activity and common mental disorders. Br J Psychiatry 2010, 197:357-364.

37. Hensing G: Chapter 4. Methodological aspects in sickness-absence research. Scand I Public Health 2004, 32:44-48.

38. Langhammer A, Krokstad S, Romundstad P, Heggland J, Holmen J: The HUNT study: participation is associated with survival and depends on socioeconomic status, diseases and symptoms. BMC Med Res Methodol 2012, 12:143.

39. Knudsen AK, Hotopf M, Skogen JC, Øverland S, Mykletun A: The health status of nonparticipants in a population-based health study the Hordaland Health Study. Am J Epidemiol 2010, 172:1306-1314.

40. Prince M, Stewart R, Ford T, Hotopf M: Meausurement in psychiatry, Practical Psychiatric Epidemiology. New York: Oxford University Press Inc; 2003:155-175.

41. Knudsen AK, Mykletun A: Rapport 2009:4 Tapte arbeidsår ved uførepensjonering for psykiske lidelser [Report 2009:4 Working years lost due to disability pensioning for mental disorders], Book Rapport 2009:4 Tapte arbeidsår ved uførepensjonering for psykiske lidelser [Report 2009:4 Working years lost due to disability pensioning for mental disorders. Nasjonalt folkehelseinstitutt: Norwegian Institute of Public Health; 2009.

42. Hoeymans N, Feskens EJM, Van Den Bos GAM, Kromhout D: Non-response bias in a study of cardiovascular diseases, functional status and self-rated health among elderly men. Age Ageing 1998, 27:35-40

doi:10.1186/1756-0500-6-27

Cite this article as: Myrtveit et al:: How accurate are self-reported pensions and benefits? A population based validation study: the NordTrøndelag health study (HUNT). BMC Research Notes 2013 6:27.

\section{Submit your next manuscript to BioMed Central and take full advantage of:}

- Convenient online submission

- Thorough peer review

- No space constraints or color figure charges

- Immediate publication on acceptance

- Inclusion in PubMed, CAS, Scopus and Google Scholar

- Research which is freely available for redistribution 